\title{
Investigating the role of salivary cortisol on vocal symptoms
}

Sofia Holmqvist Jämsén ${ }^{1}$, Ada Johansson ${ }^{2,1}$, Pekka Santtila ${ }^{1}$, Lars Westberg ${ }^{3}$, Bettina von der Pahlen $^{1}$, Susanna Simberg ${ }^{1,4}$

${ }^{1}$ Faculty of Arts, Psychology and Theology, Åbo Akademi University, Turku, Finland

${ }^{2}$ Department of Psychology and Speech-Language Pathology, Faculty of Social Sciences, University of Turku, Turku, Finland

${ }^{3}$ Department of Pharmacology, Institute of Neuroscience and Physiology, Sahlgrenska Academy, University of Gothenburg, Gothenburg Sweden

${ }^{4}$ Department of Special Needs Education, Faculty of Educational Sciences, University of Oslo, Norway

Corresponding author

Sofia Holmqvist Jämsén

Fabriksgatan 2

$20500 \AA$ Åbo

soholmqv@abo.fi

tel.+358408411386

Preliminary results of this research were presented in a poster session at the following meeting:

Pan-European Voice Conference PEVOC 11, 31.8-2.9.2015, Florence, Italy 


\begin{abstract}
Purpose: We investigated whether participants who reported more often occurring vocal symptoms showed higher salivary cortisol levels and if such possible associations were different for men and women.
\end{abstract}

Method: The participants $(N=170$; $\operatorname{men} n=49$, women $n=121)$ consisted of a populationbased sample of Finnish twins born between 1961 and 1989. The participants submitted saliva samples for hormone analysis and completed a web-questionnaire including questions regarding the occurrence of six vocal symptoms during the past 12 months. The data were analyzed using the Generalized Estimated Equations (GEE) method.

Results: A composite variable of the vocal symptoms showed a significant positive association with salivary cortisol levels $(p<.001)$. Three of the six vocal symptoms were significantly associated with the level of cortisol when analyzed separately ( $p$-values below $.05)$. The results showed no gender difference regarding the effect of salivary cortisol on vocal symptoms.

Conclusions: There was a positive association between the occurrence of vocal symptoms and salivary cortisol levels. Participants with higher cortisol levels reported more often occurring vocal symptoms. This could have a connection to the influence of stress on vocal symptoms since stress is a known risk factor of vocal symptoms and salivary cortisol can be seen as a biomarker for stress.

Key words: vocal symptoms, salivary cortisol, gender 


\section{Introduction}

Salivary cortisol is seen as a biomarker of psychological stress (Hellhammer, Wüst \& Kudielka, 2009). The stress response in itself is a protective mechanism, however, if activated frequently or over a long period of time it can have harmful effects on health. Enhanced early morning free cortisol levels have been associated with various aspects of acute (Dickerson \& Kemeny, 2004) and chronic stress (Pruessner, Hellhammer, Pruessner \& Lupien, 2003; Wüst, Federenko, Hellhammer \& Kirschbaum 2000a, Wüst, Wolf, Hellhammer, Federenko, Schommer, \& Kirschbaum, 2000b).

Cortisol is released during stress and previous studies suggest that stress is a risk factor in developing vocal symptoms or dysphonia (Baker, 2008; Dietrich, Verdolini Abbott, GartnerSchmitdt \& Rosen, 2008; Dietrich \& Verdolini Abbott, 2012; Chen, Chiang, Chung, Hsiao \& Hsiao, 2010; Gassull, Casanova, Botey, Amador, 2010; Lyberg Åhlander, 2011; Lyberg Åhlander, Pelegrín García, Whitling, Rydell \& Löfqvist, 2014; Rantala, Hakala, Holmqvist \& Sala, 2012). About 23-25\% of individuals seeking care for voice disorders or with common vocal pathologies show stress scores deviating upwards from normal scores (Dietrich et al., 2008; Misono et al., 2014).

\section{Stress and vocal symptoms}

Studies investigating acute stress have shown both acoustic and perceptual effects of stress on the voice (Giddens, Barron, Byrd-Craven, Clark, \& Winter, 2013; Mendoza \& Carballo 1998; Mendoza \& Carballo 1999; Schneider et al., 2006; Van Lierde, Van Heule, De Ley, Mertens $\&$ Claeys, 2009). The results vary and the individual differences of acoustic changes in the voice due to acute stress seem to be large. Vocal symptoms that have been reported as associated with stress are among others muscle tension, pain on phonation, pain during swallowing, hoarseness and vocal fatigue (Verdolini, Rosen \& Branski, 2006).

To be able to prevent and successfully treat voice disorders with direct or indirect links to stress we need to know more about why and how stress is associated with vocal symptoms. The Psychobiological Framework of Voice Disorders by Dietrich and Verdolini Abbott (2008, p. 161), describing pathways of the relation between stress and laryngeal behavior and voice disorders, has together with the revised psychobiological framework by Helou (2014, p. 152) provided a reliable frame of reference for studying stress and its relationship to voice. These frameworks propose the engagement of neuroendocrine responses (hypothalamic 
pituitary adrenocortical axis, HPA, and sympathetic adrenal medulla, SAM, system), the autonomic nervous system (ANS) and the somatic motor system (the reader is kindly referred to Helou, 2014 for a detailed presentation of the two frameworks). Especially the role of the ANS and/or SAM on the laryngeal muscles (Dietrich, 2008; Dietrich \& Verdolini Abbott 2012; 2014; Helou, Wang, Ashmore, Rosen, \& Verdolini Abbott, 2013) and lower airways (Helou, 2014) has been studied in relation to these two frameworks. One way to further broaden the knowledge regarding the psychobiological pathways relevant for laryngeal functioning within these frameworks is to analyze the role of cortisol on voice symptoms, since the HPA-axis might have an effect on for example immunological changes. The association between cortisol and voice symptoms has, to the best of our knowledge, not been done previously.

\section{Physiological pathways of cortisol and its possible influence on voice}

The release of cortisol is regulated by the hypothalamic pituitary adrenocortical (HPA) axis. Whereas the neurotransmitters epinephrine and norepinephrine, regulated by the sympathetic adrenal medulla (SAM) system, is part of a rapid stress reaction, cortisol is involved in a slower stress response (Lundberg, 2005). This involves a stress-induced activation of the corticotrophin releasing factor (CRF) and arginine vasopressin (AVP) neurons in the paraventricular nucleus of the hypothalamus resulting in a release of adrenocorticotropic hormone $(\mathrm{ACTH})$ from the pituitary and of cortisol from the adrenal cortex which is finally represented by salivary cortisol levels (Hellhammer et al., 2009). Cortisol is a vital hormone which influences physiological and psychological health. Typical cortisol patterns involves distinct variations during the day, where the cortisol peaks prior to awakening (Levine, Zagoory-Sharon, Feldman, Lewis \& Weller, 2007) or 30-45 min after awakening (cortisol awakening response, CAR) (Ranjit, Young, Raghunathan \& Kaplan, 2005), declines throughout the day and reaches its lowest levels in the night. According to Kristenson, Garvin and Lundberg (2011) it is not uncommon that the peak values in the morning are 10-folds higher than the values during the night.

As described in the Allostatic Load Model (McEwen, 1998), stress responses can be both beneficial and harmful. Allostasis refers to physiological adaptive responses to a potentially stressful event. When these vital adaptive responses are activated and deactivated in a balanced way, the body is able to cope efficiently with environmental demands. However, a rapid shut-down is essential for recovery. Allostatic Load is the condition where the adaptive 
responses or allostatic systems are overstimulated (frequent stress or failed shut-down), are abnormal or fail to activate (lack of stress response due to exhaustion) (Lundberg, 2002). As a result of the repeated activation without time for recovery there is an overexposure to stress hormones which over time leads to a dysregulation of the stress response. Research results show an association between the magnitude of the morning rise and the level of life stressors (Pruessner, Hellhammer \& Kirschbaum, 1999; Wüst et al., 2000a). In line with the Allostatic Load Model, results showed that severe chronic stress or burnout was associated with lack off or attenuated peak in the morning cortisol levels (Lennartsson et al., 2015).

Ongoing cortisol secretion and long-term stress is associated with various symptoms, along with reduced immune function that might have consequences for voice production. Acute stress improves wound healing and resistance to infection (Dhabhar \& McEwen, 1996) while chronic stress or high allostatic load is immunosuppressive (Dhabhar, 2000). Psychological stress and elevated cortisol levels can have an impact on wound repair (Christian, Grahamf, Padgetta, Glasera \& Kiecolt-Glaser, 2006; Gouin \& Kiecolt-Glaser, 2011), this has been confirmed also regarding mucosal wounds (Bosch, Engeland, Cacioppo \& Marucha, 2007). The mechanism might be linked to proinflammatory cytokines, which play an important role in the wound healing process, protecting the wound site from infection and preparing the wound for repair (Glaser, 2005).-Glaser, Kiecolt-Glaser, Marucha, MacCallum, Laskowski and Malarkey (1999) found that participants who had higher levels of salivary cortisol had lower levels of proinflammatory cytokines. Ebrecht et al. (2004) found that the morning cortisol response of the day after a dermal biopsy was negatively correlated with speed of wound healing. As proposed by the psychobiological framework (Dietrich \& Verdolini Abbott, 2008) and discussed by Dietrich (2008), findings regarding immunological changes as a result of stress or increased cortisol levels could be relevant for the voice domain in relation to laryngeal wound healing and changes on the vocal folds due to phono trauma.

The association between increased muscle tension and acute and/or long-term stress has been affirmed by several studies both in laryngeal regions (Baker, Ben-Tovim, Butcher, Esterman, \& McLaughlin, 2012; Baker, 2008; Dietrich \& Verdolini Abbott, 2012; 2014; Helou et al., 2013; Holmqvist, Santtila, Lindström, Sala \& Simberg, 2013) and in neck and shoulders (Lundberg; 1994, Lundberg, \& Cooper, 2011). This relationship has been explained by Helou (2013) as "stress-induced acoustic changes in the voice are dynamic modifications to functions of respiratory, intrinsic laryngeal, extrinsic laryngeal, and the supralaryngeal 
muscles”. Lundberg et al. (1994) found a significant increase electromyographic (EMG) activity in the trapezius muscle induced by mental stress, which included elevated salivary cortisol levels. However, in that study the cortisol levels was used as a biomarker of stress and the aim was not to investigate the independent effect of cortisol on trapezius muscle activity.

\section{The role of gender in voice, cortisol and stress}

It is well established that voice disorders occur significantly more often among women than among men (Coyle, Weinrich, \& Stemple, 2001; Herrington-Hall, Lee, Stemple, Niemi \& McHone, 1988; Roy, Merrill, Gray \& Smith, 2005). Dietrich et al. (2008) concluded that individual differences seem to play a role in the evolvement of stress in persons with voice disorders and that these differences may to some extent be related to gender. Gender differences in functional voice disorders have their explanations in anatomical differences (Titze, 1994; Titze, Hunter, \& Svec, 2007) and possible differences in hyaluronic acid distribution in the vocal folds (Butler, Hammond, \& Gray, 2001; Ward, Thibeault \& Gray, 2002). Additional explanations may include higher vocal effort in women (Södersten, Ternström, \& Bohman, 2005) and the fact that women are overrepresented in occupations with many voice ergonomic risk factors (Vilkman, 2004). Research concerning gender difference in occurrence of vocal symptoms and stress (Holmqvist et al., 2013), results regarding functional dysphonia (Baker, 2008), primary muscle tension dysphonia research (Dietrich et al., 2008) as well as research with no limitation on the type of voice disorders (Misono et al., 2014) showed higher occurrence of stress and vocal symptoms in women than in men.

Gender differences also exist concerning cortisol secretion (Garvin, Hurwitz Eller \& Harris, 2011; Swaab, Bao \& Lucassen, 2005; Wüst et al., 2000b), the experience of stress (Cohen \& Janicki-Deverts, 2012) and concerning consequences of stress and stress coping (Lundberg \& Cooper, 2011). In a review by Swaab et al (2005) the results showed that women had higher cortisol levels than men. In a more recent review, concerning salivary cortisol levels and demographic variables (Garvin et al., 2011), the authors concluded that there were no large differences between men and women in levels of cortisol. However, tendencies were found that women in general have somewhat higher levels than men but that men, regarding some stressors, have higher cortisol responses in laboratory stress test settings. Wüst et al. (2000b) found that gender significantly influenced early morning free cortisol levels. Given these 
differences, it is important to include gender in models analyzing effects of cortisol and/or stress on vocal symptoms.

\begin{abstract}
Aims
The aim of the present study was to explore the role of cortisol in the occurrence of vocal symptoms. We investigated whether participants who reported more often occurring vocal symptoms showed higher salivary cortisol level and hypothesized that the occurrence of vocal symptoms and cortisol levels would have a positive association. Of interest was also to investigate if such possible associations were similar for men and women. We wanted also to analyze to what extent cortisol might have effects or associations independent of stress on vocal symptoms. No study has yet investigated the role of salivary cortisol on the occurrence of vocal symptoms.
\end{abstract}

\title{
Method
}

\section{Participants}

The participants $(N=170$; men $n=49$, women $n=121)$ consisted of a population-based sample of Finnish twins born between 1961 and 1989, who submitted saliva samples for hormone analyses and completed a web-questionnaire. The sample was a subset of the Genetics of Sexuality and Aggression sample (Johansson et al., 2013). A total of 1728 twins of that cohort participated in a study exploring genetic and environmental effects in dysphonia (Simberg, Santtila, Soveri, Varjonen, Sala \& Sandnabba, 2009). Participants were recruited in two ways; participants born 1961-1971 (response rate 53\%) and participants born 1972-1989 (response rate $21 \%$ ). The sample and data collection procedure has been described in more detail in Simberg et al. (2009). The most common occupations in the sample from Simberg et al. (2009) were service occupations, medical care occupations, office workers and teaching occupations. Other common occupations were information technology programmers and analysts, engineers, factory workers and electricians. For estimates of genetic and environmental effects on vocal symptoms using the present sample the reader is kindly referred to Simberg et al (2009) and Nybacka, Simberg, Santtila, Sala, and Sandnabba (2012). 


\section{Instruments}

The participants completed a web-questionnaire including items regarding the occurrence of six vocal symptoms during the past 12 months. These vocal symptoms were; Voice becomes strained or tired, Voice becomes hoarse or low in pitch, Voice breaks while talking, Difficulty in being heard, Throat clearing or coughing while talking and Sensation of muscle tension or a lump in the throat, nowadays referred to as Screen6 (Ohlsson, Andersson, Södersten, Simberg, \& Barregård, 2012). The participants reported how often these vocal symptoms had occurred by choosing one of the alternatives daily, weekly, less frequent or never (coded from never $=0$ to daily $=3$ ). The same vocal symptoms have been used in several studies (Nybacka, et al., 2012; Sala, Laine, Simberg, Pentti, \& Suonpää, 2001; Simberg, Sala, Tuomainen, Sellman \& Rönnemaa, 2006; Simberg et al., 2009) and validated against examination performed by a laryngologist regarding organic changes on the vocal folds (Sala et al., 2001). Results from two control clinical trials (using the same retrospective questionnaire) have shown that the occurrence of vocal symptom remain over time (Simberg et al., 2006) or might increase over time (Ohlsson, Andersson, Södersten, Simberg, Claesson \& Barregård, 2015) if left untreated.

A composite variable was calculated based on the sum of all six vocal symptoms (range 0-18, with higher values indicating more vocal symptoms). Since a factor analysis is more reliably conducted on a larger research sample we did not conduct a new analysis for the present study, but chose to refer to previous results. The composite variable was created based on results from a factor analysis (using principal components as extraction method) in a study by Simberg et al. (2009) were an overlapping sample $(N=1728)$ and the same voice-variable set was used. A one-factor solution was used and the resulting scale was highly reliable (Cronbach's $\alpha=.84)$.

We also conducted a dichotomous variable where the sample was divided into participants showing at least two frequently (weekly or daily) occurring vocal symptoms and participants showing only one frequently occurring voice symptom or several vocal symptoms occurring less frequently (seldom or never). This cut-off has been used in several studies and has proven to be clinically relevant (Fellman \& Simberg,; Ohlsson et al., 2012; Ohlsson et al., 2015; Pekkarinen, Himberg, \& Pentti; 1992; Sala et al., 2001; Simberg, S., Sala, Vehmas, \& Laine, 2005; Simberg, Udd, \& Santtila, 2015). 
The questionnaire also included a question regarding exhaustion, Do you feel strained or exhausted?, to which the participant could answer yes or no. This question was included as a variable to analyze the independent effect of cortisol on vocal symptoms while taking exhaustion into account. The question has been used in previous studies (Holmqvist et al., 2013) as a measure of stress and followed the guidelines of the Tuohilampi Questionnaire (Susitaival \& Husman, 1997) a pool of questions and question sets for epidemiologic studies designed for the Finnish Institute of Occupational Health.

\section{Salivary cortisol}

A Salivette ${ }^{\circledR}$ (SARSTEDT AG \& Co., Nümbrecht, Germany) hormone sampling kit was used when collecting the saliva samples. Two collection tubes were sent to each participant and they were advised to provide saliva samples in the morning immediately after waking up, preferably before 9 a.m. They were also advised not to eat, drink, brush their teeth, or take any medication prior to giving the samples. Altogether $86.5 \%$ of the participants reported having given the saliva sample before 9 a.m. $(M=7: 50$ a.m., $S D=86 \mathrm{~min})$. The participants were advised to follow the manufacturer's instructions and to deposit approximately $2 \mathrm{~mL}$ of saliva into both collection cups. Participants were also asked to respond to a number of questions related to the time point of giving the samples. Additionally, participants were advised to return the samples strait away and if this was not possible they were to keep them in -20 degrees Celsius and return them as soon as possible. When the samples were returned, they were kept at -80 degrees Celsius until analyzed. The extraction of cortisol levels (absolute values, $\mathrm{nmol} / \mathrm{L}$ ) from the saliva samples was carried out at the Sahlgrenska University Hospital, Clinical Chemistry in Gothenburg, Sweden. They used a radioimmunoassay (RIA) method of analysis, with no specific consideration of the intensity of the cortisol awakening response (CAR). A number of 170 participants of the total 1728 who completed the web-questionnaire regarding the occurrence of six vocal symptoms (Simberg et al. 2009), submitted saliva samples.

\section{Statistical analysis}

For all statistical analyses, SPSS 21 for Windows was used (SPSS Inc., Chicago, IL, USA). The cortisol values were winsorized to reduce the effect of potentially spurious outliers by setting outliers to $3 S D$ from the mean. Observations from members of the same family can be clustered due to shared genetic or environmental factors. Therefore, we chose a method which takes into account the potential inter-dependence between subjects. The Generalized 
Estimating Equations (GEE) method is an extension to the Generalized Linear Model to data with an unknown correlation structure between the measurements, making it possible to include all siblings and twins from a family in the analyses (Hanley, Negassa, Edwardes, \& Forrester, 2003). The robust variance estimator in combination with the GEE is fairly robust in yielding consistent and asymptotically normally distributed parameter estimates, also in cases where the working correlation matrix is misspecified (Gardiner, Luo \& Roman, 2009). Since vocal symptoms were more frequent among women and cortisol levels were higher for women, gender was added as covariate in the GEE analysis. In addition to $B$ values form the GEE, we report Pearson's correlations as a way of depicting the effect size estimate to clarify the results of the GEE analysis.

\section{Ethical considerations}

The research was conducted with the approval of the Ethics Committee of the Department of Psychology at Abo Akademi University, in accordance with the Helsinki Declaration, and the Ethics Committee of the Abo Akademi University. Participation in the study was voluntary and participants could withdraw from the study at any time. No social security number or other identification data was asked and no invasive examinations were made.

\section{Results}

\section{Descriptive statistics}

The vocal symptoms and their occurrence during the past 12 months are presented in table 1. Of the 170 participants $23.6 \%$ reported frequently occurring (that is to say, weekly or more often) throat clearing, $15.9 \%$ had sensations of tension or a lump in the throat, $14.2 \%$ reported that their voice become hoarse or low in pitch, $13 \%$ reported that their voice become strained or tired, $12.3 \%$ reported difficulty in being heard, and $8.3 \%$ reported that they had voice breaks while talking. The composite variable showed a mean value of $4.50(S D=3.40)$. In this sample women $(M=4.84, S D=3.44)$ had more often occurring vocal symptoms (Wald $\left.\chi^{2}=4.51, B=4.84, p=.03\right)$ than men $(M=3.65, S D=3.19)$. The levels of salivary cortisol ranged from 1.7 to $104.76 \mathrm{nmol} / \mathrm{L}(M=20.27, S D=12.92)$. In this sample, women $(M=$ 21.89, $S D=15.38$, ) had higher salivary cortisol levels than men $(M=18.46, S D=9.80)$, with the difference showing tendency towards statistical significance (Wald $\chi^{2}=3.01, B=21.90, p$ $=.08)$. 
Table 1 . Vocal symptoms occurring during the 12 past months $(N=170)$.

\begin{tabular}{|c|c|c|c|c|c|c|c|c|c|c|c|c|}
\hline \multirow[t]{2}{*}{ Vocal symptoms } & \multicolumn{2}{|c|}{ Daily } & \multicolumn{2}{|c|}{ Weekly } & \multicolumn{2}{|c|}{$\begin{array}{l}\text { More } \\
\text { seldom }\end{array}$} & \multicolumn{2}{|c|}{ Never } & \multicolumn{2}{|c|}{$\begin{array}{c}\text { Women } \\
(n=121)\end{array}$} & \multicolumn{2}{|c|}{$\begin{array}{c}\text { Men } \\
(n=49)\end{array}$} \\
\hline & $n$ & $\%$ & $n$ & $\%$ & $n$ & $\%$ & $n$ & $\%$ & $M$ & $S D$ & $M$ & $S D$ \\
\hline $\begin{array}{l}\text { Composite variable } \\
\text { (sum of symptoms) }\end{array}$ & - & - & - & - & - & - & - & - & 4.84 & 3.44 & 3.65 & 3.19 \\
\hline $\begin{array}{l}\text { Throat clearing or } \\
\text { coughing while } \\
\text { talking }\end{array}$ & 9 & 5.3 & 31 & 18.3 & 95 & 56.2 & 34 & 20.1 & 1.13 & 0.78 & 0.98 & 0.75 \\
\hline $\begin{array}{l}\text { Sensation of muscle } \\
\text { tension or a lump in } \\
\text { the throat }\end{array}$ & 8 & 4.7 & 19 & 11.2 & 70 & 41.2 & 73 & 42.9 & 0.84 & 0.85 & 0.61 & 0.76 \\
\hline $\begin{array}{l}\text { Voice becomes } \\
\text { hoarse or low in } \\
\text { pitch }\end{array}$ & 3 & 1.8 & 21 & 12.4 & 70 & 41.2 & 76 & 44.7 & 0.74 & 0.78 & 0.63 & 0.67 \\
\hline $\begin{array}{l}\text { Voice becomes } \\
\text { strained or tired }\end{array}$ & 2 & 1.2 & 20 & 11.8 & 68 & 40.0 & 80 & 47.1 & 0.74 & 0.74 & 0.49 & 0.68 \\
\hline $\begin{array}{l}\text { Difficulty in being } \\
\text { heard }\end{array}$ & 8 & 4.7 & 13 & 7.6 & 66 & 38.8 & 83 & 48.8 & 0.73 & 0.83 & 0.57 & 0.76 \\
\hline $\begin{array}{l}\text { Voice breaks while } \\
\text { talking }\end{array}$ & 4 & 2.4 & 10 & 5.9 & 66 & 38.8 & 90 & 52.9 & 0.66 & 0.74 & 0.37 & 0.60 \\
\hline
\end{tabular}

\section{Associations between vocal symptoms and cortisol}

The composite variable of the vocal symptoms showed a significant positive association to salivary cortisol levels (Wald $\chi^{2}=10.991, d f=1, p<.001, B=0.058, S E=0.0174 ; r=.226$, $p<.003$ ), indicating that higher levels of cortisol were associated with more vocal symptoms. The vocal symptoms Difficulty in being heard (Wald $\chi^{2}=15.432, d f=1, p<.001, B=0.016$, $S E=0.004 ; r=.283, p<.001)$, Throat clearing or coughing while talking (Wald $\chi 2=8.314$, $d f=1, p<.005, B=0.013, S E=0.005 ; r=.243, p<.001$,$) and Sensation of muscle tension$ or a lump in the throat (Wald $\chi 2=4.559, d f=1, p<.05, B=0.008, S E=0.004 ; r=.146, p<$ .033) showed significant results when analyzed separately. A scatterplot including a linear regression line of the association between cortisol levels and vocal symptoms can be seen in Figure 1. 


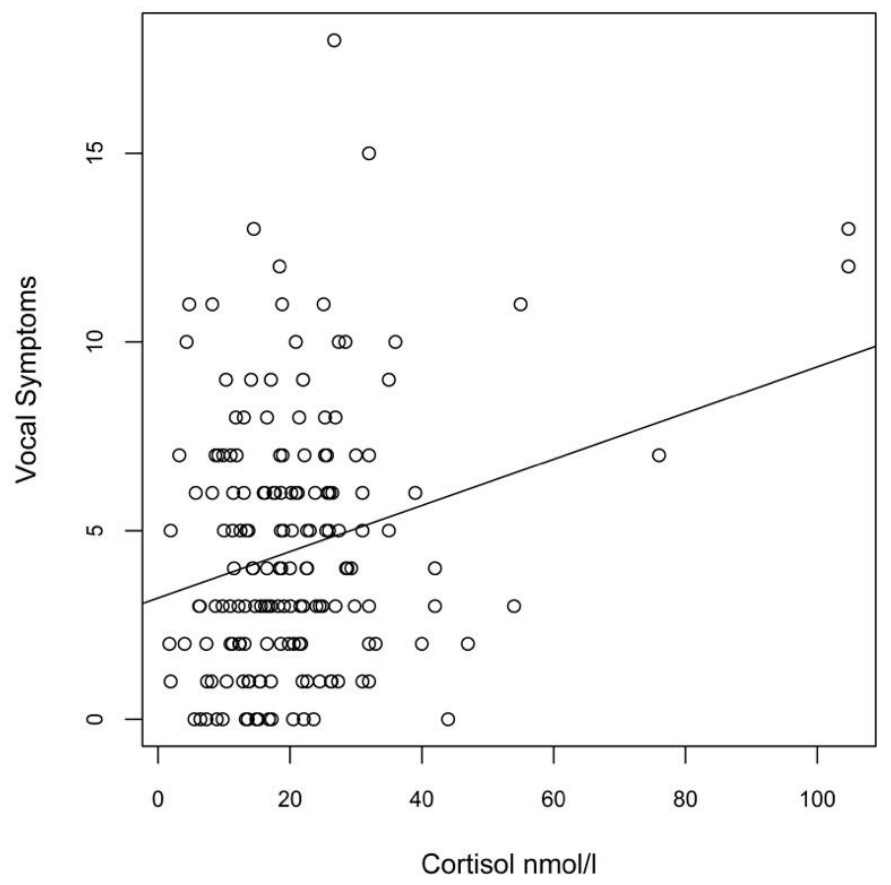

Figure 1. Scatterplot including a linear regression line of the association between cortisol levels and vocal symptoms.

Next, we tested if the effect of cortisol on vocal symptoms was similar for both genders (that is to say, the interaction between gender and cortisol on vocal symptoms). The results showed no interaction between cortisol and gender on vocal symptoms (Wald $\chi 2=0.789, d f=1, p=$ $.375)$, indicating that the association between cortisol and vocal symptoms, was similar for men and women.

Table 2. The association between cortisol and vocal symptoms ( $N=170$, gender as covariate).

\begin{tabular}{|c|c|c|c|c|c|c|}
\hline \multirow{2}{*}{ Vocal symptoms } & \multirow{2}{*}{$\begin{array}{l}\text { Pearson's } \\
r\end{array}$} & \multirow{2}{*}{ Wald $\chi 2^{a}$} & \multirow[t]{2}{*}{$B$} & \multicolumn{2}{|c|}{$C I_{95 \%}$} & \multirow[t]{2}{*}{$p$} \\
\hline & & & & lower & upper & \\
\hline Composite variable & $.226 * *$ & $10.991^{\mathrm{a}}$ & 0.058 & 0.024 & 0.092 & .001 \\
\hline Throat clearing or coughing while talking & $.243 * *$ & $8.314^{\mathrm{a}}$ & 0.013 & 0.004 & 0.022 & .004 \\
\hline $\begin{array}{l}\text { Sensation of muscle tension or a lump in the } \\
\text { throat }\end{array}$ & .146 & 4.559 & 0.008 & 0.001 & 0.015 & .033 \\
\hline Voice becomes hoarse or low in pitch & .119 & $2.002^{\mathrm{a}}$ & 0.006 & -0.002 & 0.014 & .157 \\
\hline Voice becomes strained or tired & .108 & $1.499^{\mathrm{a}}$ & 0.005 & -.003 & 0.012 & .221 \\
\hline Difficulty in being heard & $.283 * * *$ & $15.432^{\mathrm{a}}$ & 0.016 & 0.008 & 0.024 & .001 \\
\hline Voice breaks while talking & $.220 * *$ & $3.505^{\mathrm{a}}$ & 0.010 & -0.001 & 0.021 & .061 \\
\hline
\end{tabular}

$* p<.05, * * p<.01, * * * p<.001$

a $\mathrm{df}=1$ 
Next, since stress is a known risk factor for vocal symptoms, and there was an association between exhaustion and the composite variable of vocal symptoms (Wald $\chi^{2}=15.102, d f=1$, $p<.001$ ), we wanted to analyze if cortisol would have an independent effect on vocal symptoms when controlling for exhaustion as a covariate. When including exhaustion as a covariate, the magnitudes of the effects (unstandardized regression coefficients, see Table 3) where somewhat lower in comparison to when exhaustion was not a covariate, however, the confidence intervals for the effect of cortisol on vocal symptoms were overlapping between the two models (see Tables 2 and 3). The effect of cortisol was no longer significant (Wald $\chi^{2}$ $=3.023, d f=1, p=.082, B=0.050, S E=0.029)$ when controlling for the effect of exhaustion, but this could partly be explained by the fact that 58 individuals had missing information on exhaustion, and so the statistical power to find significant effects was reduced given the lower sample size $(n=112)$. The association between exhaustion and cortisol was not significant (Wald $\chi^{2}=0.101, d f=1, p=.750, B=0.006, S E=0.017$ ).

Table 3 . The association between cortisol and vocal symptoms $(N=112)$ when controlling for the effects of gender and exhaustion.

\begin{tabular}{lcccccc}
\hline \multirow{2}{*}{ Vocal symptoms } & Wald & $B$ & & \multicolumn{2}{c}{$C I_{95 \%}$} & \\
& $\chi^{2}$ & & & & \\
\cline { 3 - 6 } & & & Lower & Upper & \\
\hline Composite variable & $3.023^{\mathrm{a}}$ & 0.050 & -0.006 & 0.107 & .082 \\
Throat clearing or coughing while talking & $1.537^{\mathrm{a}}$ & 0.009 & -0.005 & 0.024 & .215 \\
Sensation of muscle tension or a lump in the throat & $1.435^{\mathrm{a}}$ & 0.008 & -0.005 & 0.020 & .231 \\
Voice becomes hoarse or low in pitch & $1.188^{\mathrm{a}}$ & 0.009 & -0.007 & 0.024 & .276 \\
Voice becomes strained or tired & $0.931^{\mathrm{a}}$ & 0.005 & -0.006 & 0.016 & .335 \\
Difficulty in being heard & $3.379^{\mathrm{a}}$ & 0.0063 & -0.001 & 0.024 & .066 \\
Voice breaks while talking & $0.736^{\mathrm{a}}$ & 0.008 & -0.010 & 0.026 & .391 \\
\hline$* p<.05, * * p<.01, * * * p<.001$ & & & & & &
\end{tabular}

Lastly, we constructed a dichotomous variable for vocal symptoms comparing individuals showing two or more vocal symptoms weekly or more frequently (a suggested cut-off for clinically relevant levels of vocal symptoms; Ohlsson et al., 2015; Sala et al., 2001) against others. The mean cortisol level for individuals showing at least two symptoms frequently was $M=26.77(S E=4.04)$ whereas it was $M=18.68(S E=0.90)$ for others $($ Wald $\chi 2=3.667, d f$ $=1, p=.056, B=-8.089, S E=4.224)$. 


\section{Discussion}

In the present study, the association between self-reported vocal symptoms and salivary cortisol levels in a population-based sample was explored. Of interest was also to investigate whether the possible association between salivary cortisol and vocal symptoms was different for men and women. There was a positive association between cortisol and voice symptoms indicating that participants who reported more often occurring vocal symptoms showed significantly higher salivary cortisol levels. There was no gender difference regarding the association between the occurrence of vocal symptoms and the level of cortisol.

\section{Associations between cortisol and voice symptoms}

The composite variable of vocal symptoms showed a positive association between morning salivary cortisol and vocal symptoms indicating that participants with higher levels of cortisol experienced several of the vocal symptoms included in the questionnaire or they experienced vocal symptoms more often than participants with lower levels of cortisol. As suggested by the Revised Psychobiological Framework of Voice Disorders (Helou, 2014), the fact that these symptoms were associated with higher levels of cortisol might potentially be associated with higher allostatic load. The Allostatic Load Model (McEwen, 1998) implies that higher allostatic load result in immunological changes. In accordance, immunological changes and impaired wound repair have been associated with higher levels of cortisol (Christian et al. 2006; Ebrecht et al. 2004; Gouin \& Kiecolt-Glaser, 2011). Ebrecht et al. (2004) found that the morning cortisol response of the day after a dermal biopsy was negatively correlated with speed of wound healing. The authors also concluded that this association was more likely to be caused by cortisol levels and physiological mechanisms than by compromising health behaviors, which were taken into account. However, since the state of the larynx and the vocal folds were not investigated in the present study, the possible connections to immunological changes are speculative.

When exhaustion was added as a covariate in the analysis, the effect of cortisol on vocal symptoms was somewhat lower and no longer significant. The lack of significance was likely affected by lower statistical power due to missing values in the exhaustion variable and thereby a smaller sample size. Thus, it cannot be excluded that both exhaustion and cortisol could have partially independent effects on vocal symptoms. 
Difficulty in being heard was the vocal symptom that had the strongest association to cortisol levels. An unbalanced voice production may cause an ineffective and uneconomical voice production which may result in various vocal symptoms (Morrison, Rammage \& Nichol, 2001) including vocal fatigue and difficulty in being heard. Symptoms of hoarseness and vocal fatigue have been shown to be associated with stress (Verdolini et al., 2006). A person with a healthy voice should be able to make himself/herself heard over moderate background noise during short periods of time. Elevated cortisol levels due to psychological stress may keep muscles in the back and neck activated (Lundberg et al., 1994) and this may influence the body posture, breathing pattern and muscle activity during voice production. An unbalanced voice production may make it more effortful or more difficult to use a raised voice.

The symptom Throat clearing or coughing while talking can be associated with dryness or edema on the vocal folds. Edema in the larynx can be a symptom of laryngopharyngeal reflux (LPR) (Hawkshaw, Pebdani, \& Sataloff, 2013), which in some cases is affected by increased stress (Cassileth \& Drossman; 1993; Naliboff et al., 2004, Núñez-Rodríguez \& Sivelo, 2008). Results from a study by Cho, Kim, Yim, Lee, Im \& Lee (2011) showed that corticotrophin releasing factor (CRF) which plays a major role in coordinating stress responses and the release of cortisol, appeared to have relevance in the pathophysiologic mechanism of reflux. Higher psychological stress has also been associated with greater symptom scores during upper respiratory infection (Cohen, Doyle, \& Skoner, 1999). Symptoms during an upper respiratory may include edema, throat clearing and cough. Cortisol influences immunological patterns and high cortisol levels might possibly delay recovery from upper respiratory infections leading to more symptoms like throat clearing or cough.

The third vocal symptom that showed association to higher cortisol levels was Sensation of muscle tension or lump in the throat. This is in line with Lundberg et al. (1994) who found elevated cortisol levels and increased EMG activity in the trapezius muscle induced by mental stress. Muscle tension has in previous studies shown a strong association with stress, as also proposed by the mentioned framework for voice disorders. Studies investigating back pain and head ache due to stress have shown that ongoing psychological stress may keep lowthreshold muscle units activated, leading to muscle tension and pain (Hägg, 1991, Lundberg et al., 1994). Tension in the neck and back may affects the function and balance of the voice production. Research regarding the etiology of MTD strongly supports the association 
between stress and muscle tension (Altman, Atkinson \& Lazarus 2005; Baker, 2008; Dietrich et al., 2008; Dietrich \& Verdolini Abbott 2012; Dietrich \& Verdolini Abbott, 2014; Goldman, Hargrave, Hillman, Holmberg \& Gress, 1996; Helou et al., 2013; Helou, 2014). The effect of acute stress on muscle tension in the larynx has been studied by Dietrich and Verdolini Abbott $(2012 ;$ 2014). They found that acute stress during a stress reactivity protocol influenced the muscular patterns of the larynx. These effects are, however, most likely due to the influence of SAM, ANS and somatic motor systems (Dietrich \& Verdolini; 2008) and not a direct effect of cortisol. Elevated salivary cortisol levels have also been observed in association with bruxism (Castelo, Barbosa, Pereira, Fonseca \& Gavião, 2012). Jaw clenching during the night or jaw clenching or hypertonicity in the tongue muscles during the day may influence tension in laryngeal muscles and influence voice production. This association might also be due to indirect effects of cortisol and co-occurring symptoms of stress.

The analysis of the clinically relevant dichotomous variable for vocal symptoms (comparing individuals showing two or more vocal symptoms weekly or more frequently against others; Sala et al., 2001) only showed a tendency towards statistical significance. The group with two or more frequently occurring vocal symptoms had a mean cortisol level of $26.77 \mathrm{nmol} / \mathrm{L}$ ( $S E$ $=4.04$ ). Compared to reported normative findings (absolute values of salivary free cortisol concentration nmol/L 60 min post-awakening) in healthy adults (Clow et al. 2003) were the mean cortisol level from multiple studies was $21.3 \mathrm{nmol} / \mathrm{L}$ ( $S D$ between studies $=2.2$ ), the group with two or more frequently occurring vocal symptoms had $>2 S D$ over the normative findings. This might indicate a connection regarding elevated cortisol levels and frequency and/ or severity of vocal symptoms, which would be in line with the framework suggested by Dietrich and Verdolini Abbott (2008, p.161) and Helou (2014) regarding the pathway on stress effecting voice and voice use.

\section{Gender differences}

The occurrence of vocal symptoms in this sample was comparable to the occurrence in prevalence studies regarding voice disorders (Coyle et al., 2001; Roy, Merrill, Thibeault, Parsa, Gray, \& Smith, 2004; Roy et al., 2005; Lyberg Åhlander, Rydell, Fredlund, Magnusson, Wilén, 2015). The descriptive data showed that vocal symptoms were more common among women, which is in line with previous findings (see for example Coyle et al., 2001; Roy et al., 2004; Wilson, Deary, Scott \& MacKenzie, 1995). Women also tended to show higher levels of salivary cortisol than men, although this difference did not quite reach 
statistical significance. We found no gender difference in the effect of levels of cortisol on vocal symptoms. The study needs to be replicated with a larger sample to be able to draw more conclusions regarding the effect of gender.

\section{Considerations and limitations}

Other hormones apart from cortisol are involved in the stress reaction. Epinephrine and norepinephrine are part of the SAM (rapid) stress response. The secretion of epinephrine and norepinephrine influence blood pressure and breathing, and these hormones have been shown to affect voice production, as seen by studies measuring acute stress (Helou, 2014). The peptide hormones oxytocin and vasopressin (Meyer-Lindenberg, Domes, Kirsch, \& Heinrichs, 2011) also influence the stress reaction and stress recovery. Thus, it may be that it is not only the amount of cortisol that influences the occurrence of voice symptoms, but the secretion of other hormones in combination with the changes these hormones induce in the body.

In this study the data regarding voice were based on a questionnaire. We should note some limitations of the current study as well as issues that could be assessed in future research. Retrospective self-reports of vocal symptoms were used, which could be influenced by recall bias. Examining the state of the larynx and how the vocal symptoms influence the person would give more precise knowledge about vocal symptoms. Moreover, the vocal symptoms included in the study do not only reflect the vocal function of the speaker, some are also strongly related to environmental factors such as background noise (for example Difficulty in being heard). However, using these same vocal symptoms as in earlier studies enables the authors to do comparisons, since they are widely used. These symptoms have also been validated against examination performed by a laryngologist regarding organic changes on the vocal folds.

Using saliva samples is a noninvasive method which also makes it possible to reach and study a larger group of participants. However, the cross-sectional nature of this study is a limitation and using multiple cortisol samples would have given the authors a broader picture of how stress is related to vocal symptoms. Kristenson et al. (2011) report that the correlation between cortisol levels on consecutive days has been reported to be $r=0.5$ in a number of studies, which is why mean levels over two or three days often are used to give more reliable results. Furthermore, since stress (acute stress or moderate duration of chronic stress) is 
associated with elevated morning cortisol levels (for example Clow, Thorn, Evans \& Hucklebridge, 2004) whereas burnout is associated with hypocortisolism (Lennartsson et al., 2015), a more detailed questionnaire regarding exhaustion or levels of stress might have provided the means to perform a more detailed analysis of the associations between cortisol levels, exhaustion and occurrence of vocal symptoms.

\section{Clinical implications and future research}

It is important to be aware of the complexity of the physiology and the mechanisms that can be involved in the etiology of vocal symptoms. Vocal symptoms appear in the population and vocal dysfunction affects quality of life. The voice is important and dysphonia can be a stressor especially for occupational voice users. The stress reaction is a vital function and essential for wellbeing but an unbalanced stress reaction pattern is, however, harmful. We need knowledge about how this part of our life and physiology influence voice use. Investigating these relationships in a larger population-based sample might get us closer to evidence regarding causal mechanisms. Knowledge about the psychological as well as the physiological and hormonal associations regarding stress and vocal symptoms provides a greater understanding of the pathways involved. This enables us to grasp and understand the importance of addressing these matters in voice care and preventive voice care.

Occurrence on vocal symptoms has been shown to be influenced by genetic factors (Nybacka et al., 2012, Roy et al., 2004; Simberg et al., 2009). The influence of genetic factors in vocal symptoms could be further explored. The association between stress, voice and genetic factors is an area for future research. Elevated cortisol levels may contribute to other hormone imbalances influencing voice and vocal recovery, stress sensitivity, stress reactivity. A dysregulated stress response system may lead to negative spiral also for the vocal function. The action of the corticotrophin releasing factor (CRF) on adrenocorticotropic hormone (ACTH) release is strongly potentiated by vasopressin that is produced in increasing amounts when the hypothalamic paraventricular neurons are chronically activated. Whereas vasopressin stimulates ACTH release in humans, oxytocin inhibits it. It might be of interest to investigate the influence and associations of vasopressin and oxytocin in the relation to cortisol in the occurrence of vocal symptoms. 


\section{Conclusion}

There was a positive association between levels of salivary cortisol and the occurrence of vocal symptoms. Participants who reported more often occurring vocal symptoms showed significantly higher salivary cortisol levels. We did not find any gender difference regarding this association. Our results are encouraging of further exploration of the role of stress and stress hormones in the etiology of vocal symptoms and voice disorders. 


\section{References}

Altman K., Atkinson, C., \& Lazarus, C. (2005). Current and emerging concepts in muscle tension dysphonia: a 30-month review. Journal of Voice, 19, 261-267.

Baker, J. (2008). The role of psychogenic and psychosocial factors in the development of functional voice disorders. International Journal of Speech-Language Pathology, 10, 210 230. doi:10.1080/17549500701879661

Baker, J., Ben-Tovim, D., Butcher A., Esterman, A., McLaughlin, K. (2012). Psychosocial risk factors which may differentiate between women with Functional Voice Disorder, Organic Voice Disorder and a Control group. International Journal of Speech-Language Pathology, 15, 547-563. doi:10.3109/17549507.2012.721397

Bosch, J.A., Engeland, C.G., Cacioppo, J.T., \& Marucha, P.T. (2007). Depressive symptoms predict mucosal wound healing. Psychosomatic Medicine, 69, 597-605.

Butler, J.E., Hammond, T.H., \& Gray, S.D. (2001). Gender-related differences of hyaluronic acid distribution in the human vocal fold. The Laryngoscope, 111, 907-11.

Cassileth, B.R., \& Drossman, D.A. (1993). Psychosocial factors in gastrointestinal illness. Psychotherapy and Psychosomatics, 59, 1-43.

Castelo, P.M., Barbosa, T.S., Pereira, L.J., Fonseca, F.L., Gavião, M.B. (2012). Awakening salivary cortisol levels of children with sleep bruxism. Clinical Biochemistry, 45, 651-654.

Chen, S.H., Chiang, S.C., Chung, Y.M., Hsiao, L.C., \& Hsiao, T.Y. (2010). Risk factors and effects of voice problems for teachers. Journal of Voice, 24, 183-192.

doi:10.1016/j.jvoice.2008.07.008.

Cho, Y.J., Kim, J.H., Yim, H.E., Lee, da M., Im, S.K., \& Lee, K.J. (2011). Role of corticotrophin-releasing factor in the stress-induced dilation of esophageal intercellular spaces. Journal of Korean medical science, 26, 279-283. doi: 10.3346/jkms.2011.26.2.279

Christian, L.M., Grahamf, J.E., Padgetta, D.A., Glasera, R., \& Kiecolt-Glaser J.K. (2006). Stress and Wound Healing. Neuroimmunomodulation, 13, 337-346. doi:10.1159/000104862.

Clow, A., Thorn, L., Evans, P., \& Hucklebridge, F. (2004). The awakening cortisol response: methodological issues and significance. Stress, 7, 29-37.

Cohen, S., \& Janicki-Deverts, D. (2012). Who's stressed? Distributions of psychological stress in the United States in probability samples from 1983, 2006, and 2009. Journal of Applied Social Psychology, 42, 1320-1334.

Cohen, S., Doyle, W.J., \& Skoner, D.P. (1999). Psychological stress, cytokine production, and severity of upper respiratory illness. Psychosomatic Medicine, 61, 175-180.

Coyle, S.M., Weinrich, B.D., \& Stemple, J.C. (2001). Shifts in relative prevalence of laryngeal pathology in a treatment-seeking population. Journal of Voice, 15, 424-440. 
Dhabhar, F.S. (2000). Acute stress enhances while chronic stress suppresses skin immunity. The role of stress hormones and leukocyte trafficking. Annals of the New York Academy of Sciences, 917, 876-93.

Dhabhar, F.S. \& McEwen, B.S. (1996). Stress-induced enhancement of antigen-specific cellmediated immunity. Journal of Immunology, 156, 2608-2615.

Dickerson, S. S. \& Kemeny, M. E. (2004). Acute stressors and cortisol responses: A theoretical integration and synthesis of laboratory research. Psychological Bulletin, 139, 355 391.

Dietrich, M. (2008). The effects of stress reactivity on extralaryngeal muscle tension on vocally normal participants as a function of personality (Doctoral Dissertation, University of Pittsburgh 2008).

Dietrich, M., \& Verdolini Abbott, K. (2012). Vocal function in introverts and extraverts during a psychological stress reactivity protocol. Journal of Speech, Language, and Hearing Research, 55, 973-987. doi:10.1044/1092-4388

Dietrich, M., \& Verdolini Abbott, K. (2014). Psychobiological stress reactivity and personality in persons with high and low stressor-induced extralaryngeal reactivity. Journal of Speech, Language, and Hearing Research, 57, 2076-2089.

doi: 10.1044/2014_JSLHR-S-12-0386.

Dietrich, M., Verdolini Abbott, K., Gartner-Schmidt, J., Rosen, C.A. (2008). The frequency of perceived stress, anxiety, and depression in patients with common pathologies affecting voice. Journal of Voice, 22, 472-88. doi: 10.1016/j.jvoice.2006.08.007

Ebrecht, M., Hextall, J., Kirtley, L. G., Taylor, A., Dyson, M., \& Weinman, J. (2004). Perceived stress and cortisol levels predict speed of wound healing in healthy male adults. Psychoneuroendocrinology, 29, 798-809.

Fellman, D., \& Simberg, S. (2016). Voice disorders among soccer coaches - prevalence and risk factors. Journal of Voice, pii: S0892-1997(16)00032-1. doi: 10.1016/j.jvoice.2016.02.003

Gardiner, J. S., Luo, Z., \& Roman, L. A. (2009). Fixed effects, random effects and GEE: What are the differences? Statistics in Medicine, 28, 221-239.

Garvin, P., Hurwitz Eller, N., \& Harris, A. (2011). Socioeconomic status, demographic variables and salivary cortisol in M. Kristenson, P. Garvin, U. Lundberg (Ed.) The Role of Saliva Cortisol Measurement in Health and Disease. doi: 10.2174/97816080534211120101, eISBN: 978-1-60805-342-1

Gassull, C., Casanova, C., Botey, Q., \& Amador, M. (2010). The impact of the reactivity to stress in teachers with voice problems. Folia Phoniatrica et Logopedica, 62, 35-39.

Giddens, C.L., Barron, K.W., Byrd-Craven, J., Clark, K.F., \& Winter, A.S. (2013). Vocal indices of stress: A review. Journal of Voice, 27, 390.e21-9.

doi:10.1016/j.jvoice.2012.12.010. 
Glaser, R. (2005). Stress-associated immune dysregulation and its importance for human health: a personal history of psychoneuroimmunology. Brain, Behavior, and Immunity, 19, 311.

Glaser, R., Kiecolt-Glaser, J.K., Marucha, P.T., MacCallum, R.C., Laskowski, B.F., \& Malarkey, W.B. (1999). Stress-related changes in proinflammatory cytokine production in wounds. Archives of General Psychiatry,56, 450-456.

Goldman, S. L., Hargrave, J., Hillman, R. E., Holmberg, E., \& Gress, C. (1996). Stress, anxiety, somatic complaints, and voice use in women with vocal nodules: Preliminary findings. American Journal of Speech-Language Pathology, 5, 44-54.

Gouin, J.P. \& Kiecolt-Glaser, J.K. (2011). The impact of psychological stress on wound healing: methods and mechanisms. Immunology And Allergy Clinics of North America, 31, 81-93. doi: 10.1016/j.iac.2010.09.010.

Hanley, J.A., Negassa, Abdissa, Edwardes, M.D. de B., \& Forrester, J.E. (2003). Statistical analysis of correlated data using Generalized Estimating Equations: An orientation. American Journal of Epidemiology, 157, 364-375.

Hellhammer, D.H., Wüst, S., \& Kudielka, B.M. (2009). Salivary cortisol as a biomarker in stress research. Psychoneuroendocrinology, 34, 163-171

doi: 10.1016/j.psyneuen.2008.10.026

Helou, L.B., Wang, W., Ashmore, R.C., Rosen, C.A., \& Verdolini Abbott, K. (2013). Intrinsic laryngeal muscle activity in response to autonomic nervous system activation. Laryngoscope, 123, 2756-2765. doi:10.1002/lary.24109

Helou, L. B. (2014). Intrinsic laryngeal muscle response to a speech preparation stressor: Personality and autonomic predictors (Unpublished doctoral dissertation). University of Pittsburgh, PA.

Herrington-Hall, B., Lee, L., Stemple, J., Niemi, K., \& McHone, M. (1988). Description of laryngeal pathologies by age, gender, and occupation in a treatment seeking sample. Journal of Speech and Hearing Disorders, 53, 57-64.

Holmqvist, S., Santtila, P., Lindström, E., Sala, E., Simberg, S. (2013). The association between stress and vocal symptoms. Journal of Voice, 27, 787.e1-787.e10.

doi:10.1016/j.jvoice.2013.06.012

Hägg, G. (1991). Static work loads and occupational myalgia - a new explanation model. In P.A. Anderson, D.J. Hobart and J.V. Danhoff (Ed.) Electromyographical Kinesiology (141144). Amsterdam: Elveiser Science Publishers B.V.

Johansson, A., Jern, P., Santtila, P., von der Pahlen, B., Eriksson, E., Westberg, L., Nyman, H., Pensar, J., Corander, J., \& Sandnabba, N.K. (2013). The genetics of sexuality and aggression (GSA) twin samples in Finland. Twin Research and Human Genetics, 16, 150156. doi: 10.1017/thg.2012.108. 
Kristenson, M., Garvin, P., \& Lundberg, U. (2011). The role of saliva cortisol measurement in health and disease introduction - Why this book? in M. Kristenson, P. Garvin, U. Lundberg (Eds.) The Role of Saliva Cortisol Measurement in Health and Disease (pp. 3-16) doi: 10.2174/97816080534211120101, eISBN: 978-1-60805-342-1

Lennartsson, A.-K., Sjörs, A., Währborg, P., Ljung, T., \& Jonsdottir, I. H. (2015). Burnout and Hypocortisolism - A Matter of Severity? A Study on ACTH and Cortisol Responses to Acute Psychosocial Stress. Frontiers in Psychiatry, 6, 8. http://doi.org/10.3389/fpsyt.2015.00008

Levine, A., Zagoory-Sharon, O., Feldman, R., Lewis, J.G., \& Weller, A. (2007). Measuring cortisol in human psychobiological studies. Physiology \& Behavior, 90, 43-53.

Lundberg, U., Kadefors, R., Melin, B., Palmerud, G., Hassmen, P., Engstrom, M., Dohns, I.E. (1994). Psychophysiological stress and EMG activity of the trapezius muscle. International Journal of Behavioral Medicine. 1, 354-70.

Lundberg, U. (2002). Psychophysiology of work: stress, gender, endocrine response, and work-related upper extremity disorders. American Journal of Industrial Medicine, 41, 383392. doi:10.1002/ajim.10038

Lundberg, U. (2005). Stress hormones in health and illness: the roles of work and gender. Psychoneuroendocrinology, 30,1017-1021.

Lundberg, U \& Cooper, C.L. (2011). The science of occupational health. Stress, psychobiology and the new world of work. Wiley-Blackwell: Oxford.

Lyberg Åhlander, V. (2011). Voice use in teaching environments speakers' comfort (Unpublished doctoral dissertation). Lund University, Faculty of Medicine.

Lyberg Åhlander, V., Pelegrín García, D., Whitling, S., Rydell, R., \& Löfqvist, A. (2014). Teachers' voice use in teaching environments: a field study using ambulatory phonation monitor. Journal of Voice, 28, 841.e5-15. doi: 10.1016/j.jvoice.2014.03.006

Lyberg Åhlander, V., Rydell, R., Fredlund, P., Magnusson, C., Wilén S. (2015). Prevalence of voice disorders in the general population in Sweden. Abstract presented at Pan European Voice Conference PEVOC11, September 2015.

McEwen, B. S. (1998), Stress, Adaptation, and Disease: Allostasis and Allostatic Load. Annals of the New York Academy of Sciences, 840, 33-44. doi:10.1111/j.17496632.1998.tb09546.x

Mendoza, E., \& Caballo, G (1998). Acoustic analysis of induced vocal stress by means of cognitive workload tasks. Journal of Voice, 12, 263-273

Mendoza, E., \& Caballo, G. (1999). Vocal tremor and psychological stress. Journal of Voice, 13, 105-112. 
Meyer-Lindenberg, A., Domes, G., Kirsch, P., \& Heinrichs, M. (2011). Oxytocin and vasopressin in the human brain: social neuropeptides for translational medicine. Nature Reviews Neuroscience, 12, 524-538.

Misono, S., Peterson, C.B., Meredith, L., Banks, K., Bandyopadhyay, D., Yueh, B., \& Frazier P.A. (2014). Psychosocial distress in patients presenting with voice concerns. Journal of Voice, 28, 753-761. doi: 10.1016/j.jvoice.2014.02.010.

Morrison, M.D., Rammage, L.A., \& Nichol, H. (2001). Management of the Voice and Its Disorders. 2nd ed. San Diego, California: Singular.

Naliboff, B.D., Mayer, M., Fass, R., Fitzerald, L.Z., Chang, L., Bolus, R. \& Mayer, E.A. (2004). The effect of life stress on symptoms of heartburn. Psychosomatic Medicine, 66, 426434.

Núñez-Rodríguez, M.H., \& Sivelo, A.M. (2008). Psychological factors in gastroesophageal reflux disease measured by SCL-90-R Questionnaire. Digestive Diseases and Sciences, 53, 3071-3075. doi: 10.1007/s10620-008-0276-0.

Nybacka, I., Simberg, S., Santtila, S., Sala, E., \& Sandnabba, NK. (2012). Genetic and environmental effects on vocal symptoms and their intercorrelations. Journal of Speech, Language, and Hearing Research, 55, 541-553.

Ohlsson, A-C., Andersson, E.M., Södersten, M., Simberg, S., \& Barregård, L. (2012). Prevalence of voice symptoms and risk factors in teacher students. Journal of Voice, 26, 629634.

Ohlsson, A-C, Andersson, E.M., Södersten, M., Simberg, S., Claesson , S., \& Barregård, L. (2015). Voice disorders in teacher students - a prospective study and a randomized controlled trial. Journal of Voice, pii: S0892-1997 (15) 00204-0. doi: 10.1016/j.jvoice.2015.09.004.

Pekkarinen, E., Himberg, L., \& Pentti, J. (1992). Prevalence of vocal symptoms among teachers compared with nurses: A questionnaire study. Scandinavian Journal of Logpedics and Phoniatrics, 17, 113-117.

Pruessner, J.C., Hellhammer, D.H., \& Kirschbaum, C. (1999). Burnout, perceived stress, and cortisol responses to awakening. Psychosomatic Medicine, 61, 197-204.

Pruessner, M., Hellhammer, D.H., Pruessner, J.C., \& Lupien, S.J. 2003. Self-reported depressive symptoms and stress levels in healthy young men associations with the cortisol response to awakening. Psychosomatic Medicine, 65, 92-99.

Ranjit, N., Young, E.A., Raghunathan, T.E., \& Kaplan, G.A. (2005). Modeling cortisol rhythms in a population-based study. Psychoneuroendocrinology, 30, 615-624.

Rantala, L.M., Hakala, S.J. Holmqvist, S., \& Sala, E. (2012). Connections between voice ergonomic risk factors and voice symptoms, voice handicap, and respiratory tract diseases. Journal of Voice, 26, 819.e13-819.e20. 
Roy, N., Merrill, R.M., Thibeault, S., Parsa, R.A., Gray, S.D., \& Smith, E.M. (2004). Prevalence of voice disorders in teachers and the general population. Journal of Speech, Language, and Hearing Research, 47, 281-293.

Roy, N., Merrill, R., Gray, S.D., \& Smith, E.M. (2005). Voice disorders in the general population: prevalence, risk factors, and occupational impact. The Laryngoscope, 115, 19881995.

Sala, E., Laine, A., Simberg, S., Pentti, J., \& Suonpää, J., (2001). The prevalence of voice disorders among day care center teachers compared with nurses: a questionnaire and clinical study. Journal of Voice. 15, 413-423.

Simberg, S., Sala, E., Tuomainen, J., Sellman, J., \& Rönnemaa, A-M. (2006). The effectiveness of group therapy for students with mild voice disorders: A controlled clinical trial. Journal of Voice, 20, 97-109.

Simberg, S., Sala E., Vehmas, K., \& Laine, A. (2005). Changes in the prevalence of vocal symptoms among teachers during a twelve-year period. Journal of Voice, 19, 95-102.

Simberg, S., Santtila, P., Soveri, A., Varjonen, M., Sala, E., \& Sandnabba, K. (20 09). Exploring genetic and environmental effects in dysphonia: A twin study. Journal of Speech, Language, and Hearing Research, 52, 153-163.

Simberg, S., Udd, H., \& Santtila, P. (2015). Gender differences in the prevalence of vocal symptoms in smokers. Journal of Voice, 5, 588-591.

Schneider, B., Enne, R., Cecon, M., Diendorfer-Radner, G., Wittels, P., Bigenzahn, W. \& Johannes, B. (2006). Effects of vocal constitution av autonomic stress-related reactivity on vocal endurance in female student teachers. Journal of Voice, 20, 242-250.

Susitaival, R. \& Husman, T. (1997). Eds. Tuohilampi Questionnaire. Tuohilampiryhmä, Hakapaino Oy, Helsinki.

Swaab, D.F., Bao, A.M., \& Lucassen, P.J. (2005). The stress system in the human brain in depression and neurodegeneration. Ageing Research Reviews, 4, 141-94.

Södersten, M., Ternström, S., \& Bohman, M. (2005). Loud speech in realistic environmental noise: Phonetogram data, perceptual voice quality, subjective ratings, and gender differences in healthy speakers. Journal of Voice, 19, 29-46.

Titze, I. R. (1994). Mechanical stress in phonation. Journal of Voice, 8, 99-105.

Titze, I. R., Hunter, J. E., \& Svec, J. G. (2007). Voicing and silence periods in daily and weekly vocalizations of teachers. The Journal of the Acoustical Society of America, 121, 469478.

Van Lierde, K., Van Heule, S., De Ley, S., Mertens, E. \& S. Claeys (2009). Effect of psychological stress on female vocal quality. A multiparameter approach. Folia Phoniatrica et Logopedica, 61, 105-111. 
Ward, P.D., Thibeault, S.L., \& Gray, S.D. (2002). Hyaluronic acid: its role in voice. Journal of Voice, 16, 303-309.

Verdolini, K., Rosen, C. A., \& Branski, R. C. (Eds.). (2006). Classification manual for voice disorders-1. Mahwah, NJ: Erlbaum.

Vilkman, E. (2004). Occupational safety and health aspects of voice and speech professions. Folia Phoniatrica et Logopedica, 56, 220-253.

Wilson, J.A., Deary I. J., Scott, S. \& MacKenzie, K. (1995). Functional dysfonia. Not "hysterical" but still seen mainly in women. British Medical Journal, 311, 1039-1040.

Wüst, S., Federenko, I., Hellhammer, D.H., \& Kirschbaum, C. (2000a). Genetic factors perceived chronic stress and free cortisol. Psychoneuroendocrinology, 25, 707-720.

Wüst, S., Wolf, J., Hellhammer, D.H., Federenko, I., Schommer, N. \& Kirschbaum, C. (2000b). The cortisol awakening response - normal values and confounds. Noise \& Health, 2, 79-88. 